\title{
Autophagy defends pancreatic $\beta$ cells from human islet amyloid polypeptide-induced toxicity
}

\author{
Jacqueline F. Rivera, ${ }^{1}$ Safia Costes, ${ }^{1}$ Tatyana Gurlo, ${ }^{1}$ Charles G. Glabe, ${ }^{2}$ and Peter C. Butler ${ }^{1}$ \\ 'Department of Medicine, David Geffen School of Medicine, UCLA, Los Angeles, California, USA. ²Department of Molecular Biology and Biochemistry, University of California, Irvine, California, USA.
}

\begin{abstract}
Type 2 diabetes (T2D) is characterized by a deficiency in $\beta$ cell mass, increased $\beta$ cell apoptosis, and extracellular accumulation of islet amyloid derived from islet amyloid polypeptide (IAPP), which $\beta$ cells coexpress with insulin. IAPP expression is increased in the context of insulin resistance, the major risk factor for developing T2D. Human IAPP is potentially toxic, especially as membrane-permeant oligomers, which have been observed to accumulate within $\beta$ cells of patients with T2D and rodents expressing human IAPP. Here, we determined that $\beta$ cell IAPP content is regulated by autophagy through p62dependent lysosomal degradation. Induction of high levels of human IAPP in mouse $\beta$ cells resulted in accumulation of this amyloidogenic protein as relatively inert fibrils within cytosolic p62-positive inclusions, which temporarily averts formation of toxic oligomers. Mice hemizygous for transgenic expression of human IAPP did not develop diabetes; however, loss of $\beta$ cellspecific autophagy in these animals induced diabetes, which was attributable to accumulation of toxic human IAPP oligomers and loss of $\beta$ cell mass. In human IAPP-expressing mice that lack $\beta$ cell autophagy, increased oxidative damage and loss of an antioxidant-protective pathway appeared to contribute to increased $\beta$ cell apoptosis. These findings indicate that autophagy/ lysosomal degradation defends $\beta$ cells against proteotoxicity induced by oligomerization-prone human IAPP.
\end{abstract}

\section{Introduction}

Type 2 diabetes (T2D) is characterized by loss of $\beta$ cell mass, $\beta$ cell dysfunction, and increased $\beta$ cell apoptosis (1). Islet pathology in $\mathrm{T} 2 \mathrm{D}$ is also characterized by accumulation of extracellular islet amyloid derived from islet amyloid polypeptide (IAPP) (2). IAPP is a 37-amino acid protein coexpressed and secreted by pancreatic $\beta$ cells along with insulin. While the extracellular islet amyloid is relatively inert, intracellular membrane-permeant toxic oligomers of IAPP that form within $\beta$ cells in T2D (3) are thought to induce $\beta$ cell dysfunction and apoptosis. In contrast to the human form of IAPP (h-IAPP), which is endowed with propensity to form toxic membrane-permeant oligomers, the rodent form of IAPP (r-IAPP) is nonamyloidogenic and nontoxic due to proline substitutions. Transgenic expression of h-IAPP in $\beta$ cells of rodents may lead to development of diabetes as a consequence of $\beta$ cell apoptosis and formation of intracellular IAPP oligomers comparable to those found in humans with T2D (3-7).

Since long-lived secretory cells, such as pancreatic $\beta$ cells, bear a high burden of protein synthesis and folding, the disposal of misfolded or denatured proteins, and particularly those with a potential to form toxic oligomers, is important. The autophagy/lysosome system plays a key role in cellular adaptation to stress via clearance of misfolded proteins, damaged organelles, and/or oligomerization-prone proteins (8). Notably, $\beta$ cell-specific deletion of a key autophagy initiator gene, autophagy-related protein 7 (Atg7), in

\section{Related Commentary: p. 3292}

Authorship note: Jacqueline F. Rivera and Safia Costes contributed equally to this work Conflict of interest: The authors have declared that no conflict of interest exists. Submitted: July 8, 2013; Accepted: May 23, 2014.

Reference information: J Clin Invest. 2014;124(8):3489-3500. doi:10.1172/JCI71981. mice compromises $\beta$ cell function and survival under high-fat feeding conditions $(9,10)$. Furthermore, stimulation of autophagy with rapamycin delays diabetes and attenuates $\beta$ cell apoptosis in the Akita mouse model of diabetes (11) characterized by endoplasmic reticulum stress induced by proinsulin misfolding.

The synthetic burden of both major client proteins of pancreatic $\beta$ cells, insulin and IAPP, increases in response to insulin resistance (12). Defenses against accumulation of intracellular misfolded proteins, including availability of chaperone proteins, function of the ubiquitin-proteasome and autophagy/lysosome systems, decline with aging $(13,14)$. Since insulin resistance and aging are the major risk factors for $\mathrm{T} 2 \mathrm{D}$, the probability that defense mechanisms against accumulation of misfolded proteins in $\beta$ cells will be overwhelmed mirrors the risk for development of T2D. This implies that accumulation of oligomerization-prone IAPP in $\beta$ cells that further compromises the ubiquitin-proteasome and autophagy/lysosome systems may play an important role in the development of T2D.

In prior in vitro studies, we reported that enhancement of autophagy was protective while attenuated lysosomal degradation rendered $\beta$ cells more vulnerable to h-IAPP-induced apoptosis (15). However, the involvement of autophagy in IAPP degradation and its relationship to $\beta$ cell viability and protection against diabetes is not well characterized. In this study, we first tested the hypothesis that IAPP protein content in $\beta$ cells is regulated by the autophagy/lysosome system by both investigating the variance in IAPP content under modulation of autophagic flux as well as probing the presumptive itinerary of IAPP destined for autophagy. Second, having established that autophagy is indeed an important pathway for IAPP degradation, we tested the hypothesis that in vivo concurrent loss of autophagy and $\beta$ cell expression of a usually well-tolerated level of human-IAPP induces diabetes onset. 
A
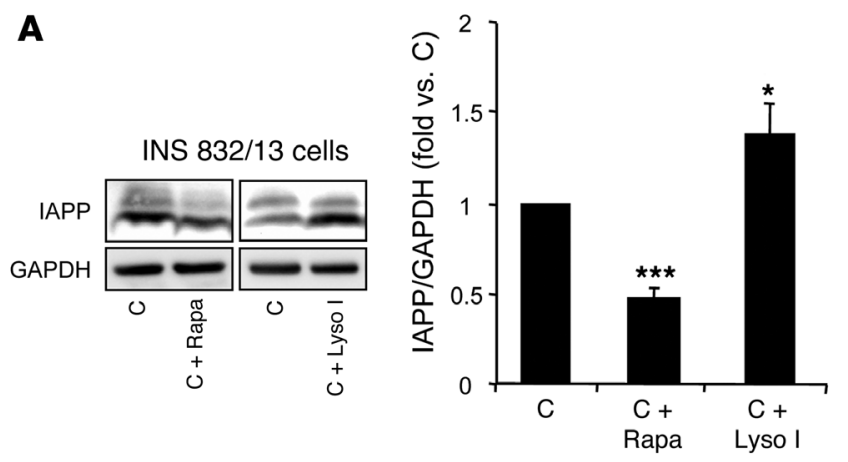

B

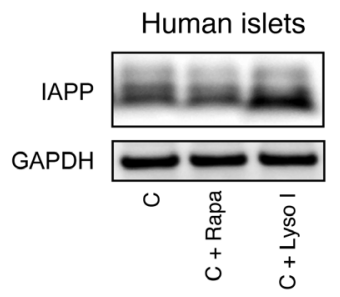

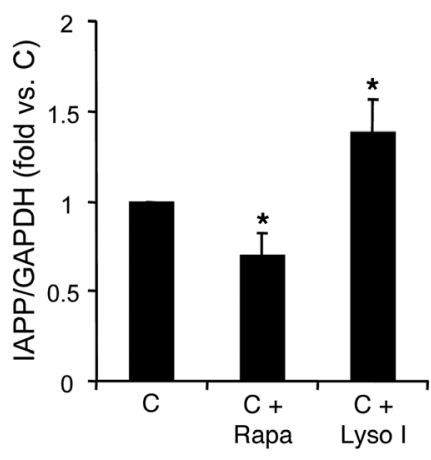

\section{Results}

The autophagy/lysosome system determines intracellular IAPP content. In a professional secretory cell such as a $\beta$ cell, intracellular secretory protein content is determined by the balance among protein synthesis, degradation, and secretion. To evaluate whether autophagy contributes to the degradation of IAPP, we investigated the effects of stimulation and inhibition of autophagy on IAPP content in $\beta$ cells. We previously reported that rapamycin and lysosomal inhibitors are efficient modulators of autophagy in $\beta$ cells (15). Stimulation of autophagy in INS 832/13 cells with rapamycin reduced $\beta$ cell IAPP content $(54 \% \pm 5.5 \%$ decrease versus nontreated cells detected by Western blot, $P<0.001$; Figure $1 \mathrm{~A}$; and $33 \% \pm 2.5 \%$ decrease detected by enzyme immunoassay, $P<0.001$; Supplemental Figure 1; supplemental material available online with this article; doi:10.1172/JCI71981DS1). In con-

Figure 1. Intracellular IAPP levels are modulated by regulators of autophagy. (A) INS 832/13 cells were treated with rapamycin (Rapa, $10 \mathrm{nM}$ ) for 40 hours, lysosomal inhibitors (Lyso I) (E-64-d, $10 \mu \mathrm{g} / \mathrm{ml}$ and pepstatin A, $10 \mu \mathrm{g} / \mathrm{ml}$ ) for 24 hours, or left untreated (C). Levels of IAPP were assessed by Western blot. GAPDH was used as loading control. The graph represents the quantification of the processed/mature form of IAPP $(n=4)$. (B) Human islets were treated with rapamycin (10 nM) for 30 hours, lysosomal inhibitors (E-64-d, $10 \mu \mathrm{g} / \mathrm{ml}$ and pepstatin $\mathrm{A}, 10 \mu \mathrm{g} / \mathrm{ml}$ ) for 30 hours, or left untreated. Levels of IAPP were assessed by Western blot. GAPDH was used as loading control. The graph represents the quantification of IAPP protein levels $(n=3)$. Data are expressed as mean $\pm \mathrm{SEM}$; ${ }^{*} P<0.05 ;{ }^{* *} P<0.001$.

trast, treatment of cells with the inhibitors of lysosomal proteases, E-64- $d$ and pepstatin A, increased $\beta$ cell IAPP content (1.4-fold versus nontreated cells, $P<0.05$; Figure $1 \mathrm{~A}$ and Supplemental Figure 1). We confirmed that these changes in IAPP content were not related to changes in IAPP expression or secretion (Supplemental Figure 2 and Supplemental Figure 3A). Altogether, these data suggest that, in rodent $\beta$ cells, IAPP content is regulated, at least in part, by autophagy.

To extend these findings to humans, we repeated the experiments using human islets. Enhancement of autophagy with rapamycin decreased cellular IAPP content $(31 \% \pm 12.4 \%$ decrease versus nontreated islets, $P<0.05$; Figure $1 \mathrm{~B})$, while inhibition of lysosome-dependent clearance led to an increase in IAPP cellular content (1.4-fold versus nontreated islets, $P<0.05$; Figure 1B). In contrast to IAPP, cellular insulin content was not affected upon treatment with either lysosomal inhibitors or rapamycin (Supplemental Figure 4), suggesting a selective targeting of IAPP to the autophagy/lysosomal pathway.

Besides rapamycin, several FDA-approved compounds with low cytotoxicity promote the degradation of long-lived proteins (16). Amiodarone and trifluoperazine induced autophagic degradation and thus reduced the accumulation of misfolded proteins in human glioblastoma H4 cells (16). Similarly, amiodarone and trifluoperazine stimulated autophagy in pancreatic $\beta$ cells and rat islets (Supplemental Figure 5, A and B). These compounds decreased cellular IAPP content and reduced h-IAPP-induced apoptosis in islets isolated from h-IAPP transgenic rats (HIP rats, a
Figure 2. IAPP interacts with p62 in $\beta$ cells. (A) INS 832/13 cells were transduced at $400 \mathrm{MOI}$ for 36 hours with r-IAPP (R) or h-IAPP (H) adenoviruses. Cell lysates were subjected to immunoprecipitation (IP) with anti-p62 antibody or IgG as control. Immunoprecipitated proteins were resolved by SDS-PAGE and immunoblotted (IB) with anti-IAPP antibody. Levels of CAPDH are shown as internal and loading control. A representative image from 5 independent experiments is shown. C, nontransduced cells (B) Islets were isolated from 9- to 10-week-old WT, r-IAPP ( $r$-TC), and homozygous h-IAPP transgenic (h-TC) mice. Islet lysates were subjected to immunoprecipitation with anti-p62 antibody or IgC as control. Immunoprecipitated proteins were resolved by SDS-PACE and immunoblotted with anti-IAPP antibody. Levels of GAPDH are shown as internal and loading control. A representative image from 3 independent experiments is shown.
A

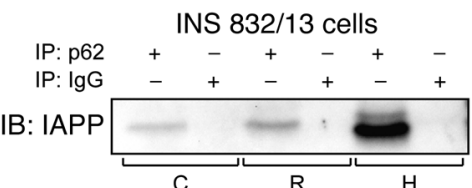

Control lysate

IB: GAPDH

C

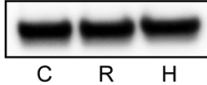

B

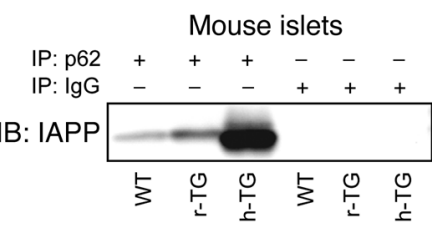

Control lysate

IB: GAPDH

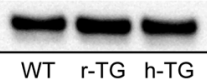


A

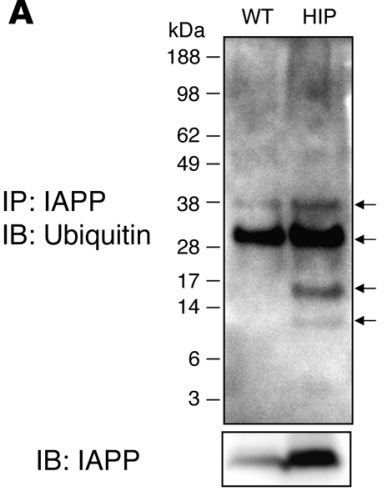

B

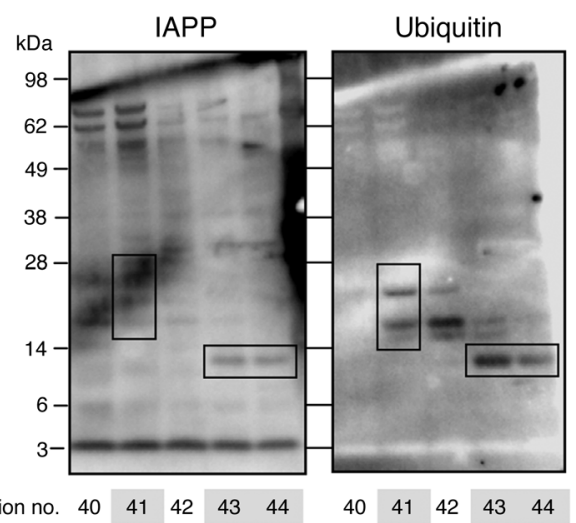

Figure 3. IAPP is ubiquitinated. (A) Islets were isolated from 4- to 6-month-old WT and HIP rats. Islet lysates were subjected to immunoprecipitation with a rabbit anti-IAPP antibody. Immunoprecipitated proteins were resolved by SDS-PACE and immunoblotted with a mouse anti-ubiquitin antibody. Levels of IAPP are shown as control. Arrows indicate polyubiquitinated IAPP $(n=3)$. (B) Islets were isolated from 4- to 6-month-old HIP rats. Insoluble fraction was obtained by a detergent extraction protocol and dissolved in $6 \mathrm{M}$ guanidine plus $0.5 \mathrm{M} \mathrm{DTT}$ for 1 hour at $37^{\circ} \mathrm{C}$. Fractions were collected by HPLC and then immunoblotted with a rabbit anti-IAPP antibody. The membrane was then stripped and immunoblotted with a mouse anti-ubiquitin antibody. A representative blot from 2 independent experiments is shown. Boxes indicate bands detected by both anti-IAPP and anti-ubiquitin antibodies.

rodent model for T2D; ref. 4) (Supplemental Figure 5C). We conclude that the autophagy/lysosome system specifically regulates intracellular IAPP content levels in human and rodent $\beta$ cells.

p62 interacts with IAPP and sequesters IAPP in $\beta$ cells. The adaptor protein p62 (also known as sequestosome 1 or SQSTM1) is involved in selective autophagic clearance of long-lived and aggregation-prone proteins (8). To test the hypothesis that $\mathrm{p} 62$ is required for IAPP degradation by autophagy, we evaluated the interaction between IAPP and p62 in INS 832/13 cells transduced with adenoviruses expressing h-IAPP or the nonamyloidogenic and nontoxic r-IAPP (used as a control for comparable burden of protein expression [Supplemental Figure 6A] as previously published; refs. 17-19). In all 3 conditions (control and r-IAPP- and h-IAPP-transduced cells), IAPP immunoprecipitated with p62 (Figure 2A). However, the proportion of IAPP associated with p62 was markedly increased in $\beta$ cells with high expression of h-IAPP versus r-IAPP (Figure 2A).

To confirm that the IAPP-p62 interaction was relevant in vivo, we performed immunoprecipitation experiments using islets from mice with transgenic $\beta$ cell expression of h-IAPP (h-TG) and islets from transgenic mice expressing comparable levels of r-IAPP (r-TG) (Supplemental Figure 6B). As we previously reported, toxic oligomers of h-IAPP form intracellularly in $\beta$ cells of h-TG mice but not r-TG mice, and only h-TG mice develop diabetes $(3,6)$. Since lysosomal degradation is impaired in $\beta$ cells of h-TG mice (15), this model characterized by p62 accumulation (Supplemental Figure 6B) provides optimal experimental conditions to investigate whether IAPP interacts with $\mathrm{p} 62$ in vivo. We found that, similar to the experiments performed in the INS $832 / 13 \beta$ cell line, IAPP immunoprecipitated with p62 in mouse islets, with a more pronounced interaction in h-TG mice (Figure 2B). The specificity of this interaction between IAPP and p62 was reinforced by the absence of binding among the even more abun-

dantly expressed $\beta$ cell secretory protein, insulin, and p62 (Supplemental Figure 7).

p62 acts as an autophagic receptor for polyubiquitinated proteins because of its ability to bind both target-associated ubiquitin and LC3 conjugated to the autophagosome membrane (8). We next sought to establish whether IAPP becomes polyubiquitinated in order to be targeted for p62-dependent lysosomal degradation. IAPP was immunoprecipitated from islet lysates from WT and HIP rats and then subjected to Western blotting for the detection of ubiquitin. Polyubiquitinated IAPP was present in WT rat islets and increased in HIP rat islets (Figure 3A). The insoluble protein fraction isolated from HIP rat islets was solubilized as described previously (20), fractionated using high-performance liquid chromatography, and subjected to Western blot analysis. In some fractions (no. 41 , no. 43 , and no. 44; Figure 3B), we detected high-molecular-weight bands positive for both IAPP and ubiquitin. In conclusion, both experimental approaches confirm the existence of a pool of polyubiquitinated IAPP.

p62 not only assists autophagic degradation of ubiquitinated proteins, but also, due to its polymeric nature, mediates protein aggregation when lysosomal degradation is limited (8). We thus investigated whether the insoluble cytoplasmic inclusions of p62 present in h-TG $\beta$ cells (15) also contain insoluble forms of IAPP. To proceed, we separated the detergent-soluble and -insoluble compartments by fractionation of islet lysates. We observed a marked increase in the levels of p62 in both the soluble and insoluble fractions in islets from h-TG mice compared with those from $\mathrm{r}$-TG mice (Figure $4 \mathrm{~A}$ ). In the soluble fraction, IAPP immunoprecipitated with p62 in both $\mathrm{r}$-TG and h-TG mouse islets but with a more pronounced interaction in h-TG mice (Figure 4B). When we examined the insoluble fraction, IAPP immunoprecipitated with p62 exclusively in h-TG mice (Figure 4B). Since insoluble h-IAPP may form amyloid fibrils, we used thioflavin S, a dye that binds to amyloid fibrils but not to soluble monomers (21), to investigate the interaction between p62 and insoluble IAPP fibrils within the cytosolic inclusions. The p62 inclusions were positive for thioflavin S, implying that IAPP sequestered within $\mathrm{p} 62$ inclusions in vivo is indeed organized into fibrils within $\beta$ cells (Figure $4 \mathrm{C}$ and Supplemental Figure 8 ). Since extracellular fibrils of amyloidogenic proteins are relatively inert in contrast to membrane-permeant oligomers (2), p62 may play an important role by favoring fibril formation of potentially toxic h-IAPP and thereby serve as a buffer to protect $\beta$ cells against h-IAPP toxicity (Supplemental Figures 9 and 10).

Of interest, confocal images revealed that these inclusions were surrounded by the autophagy machinery involving autophagosomes (LC3 staining) and lysosomes (cathepsin D staining) (Figure $4 \mathrm{D}$ ). Thus, it is tempting to speculate that the autophagosomes migrate to the much larger p62-bound aggregates and in turn attract the lysosomes. Altogether our data demonstrate that soluble and insoluble h-IAPP are targeted for p62-dependent autophagy.

Intracellular accumulation of toxic oligomers is enhanced in $\beta$ cells from autophagy-deficient human-IAPP transgenic mice. Since chem- 
A

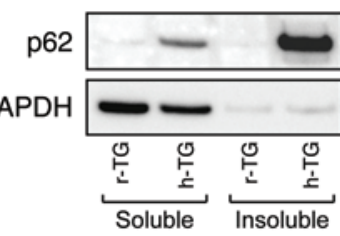

B

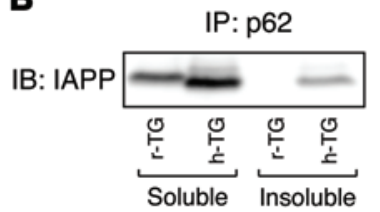

C
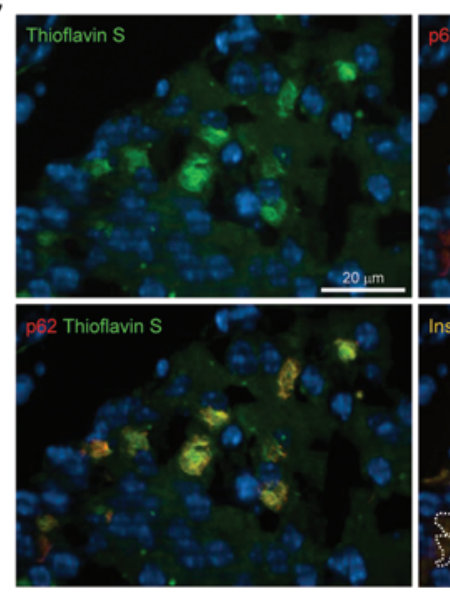
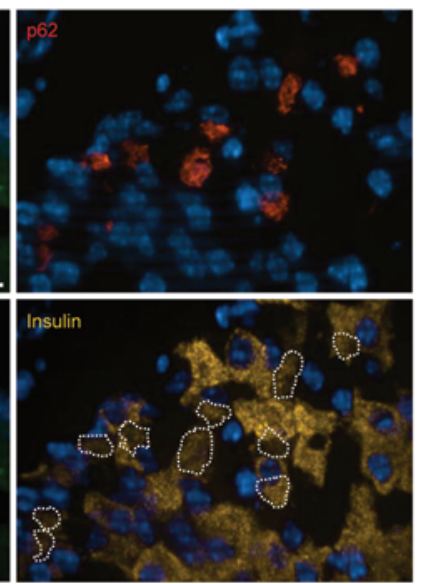
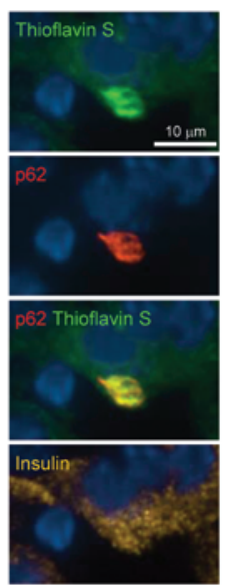

D

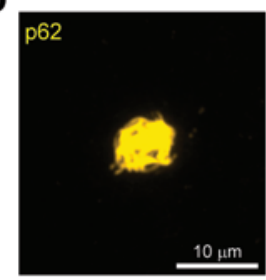

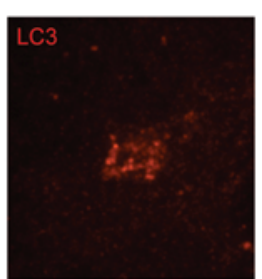

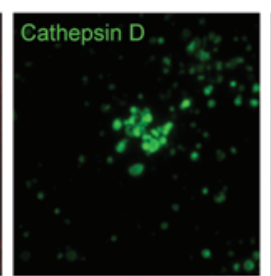

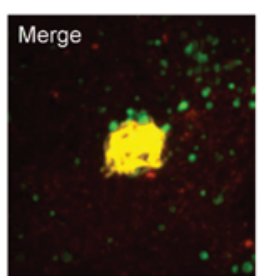

Figure 4. Insoluble p62-sequestered IAPP is targeted for lysosomal degradation. (A) Islets were isolated from 9- to 10-week-old r-TG and h-TC mice. Islet lysates were used to separate total cellular protein into soluble and insoluble fractions. Levels of p62 and IAPP were assessed by Western blot. GAPDH was used as control. A representative image from 4 independent experiments is shown. (B) Soluble and insoluble fractions from mouse islets were subjected to immunoprecipitation with anti-p62 antibody. Immunoprecipitated proteins were resolved by SDS-PAGE and immunoblotted with anti-IAPP antibody. (C) Thioflavine $S$ staining in pancreatic sections from 9- to 10-week-old h-TC mice (Thioflavin S, green; p62, red; insulin, yellow; nuclei, blue) (scale bar: $20 \mu \mathrm{m}$ ). A higher magnification of an inclusion is presented on the right (scale bar: $10 \mu \mathrm{m}$ ). The dotted outlines on the insulin panel indicate the position of thioflavin S- and p62-positive inclusions. (D) Fluorescent confocal images of p62-positive inclusion using ( $p 62$, yellow; LC3, red; cathepsin D, green) in pancreatic tissue from h-TG mice (original magnification, $\times 63)$. Scale bar: $10 \mu \mathrm{m}$. ical compounds used to manipulate autophagy may have other effects in $\beta$ cells (22-24), we used a genetic approach to corroborate that autophagy plays a key role in controlling h-IAPP levels in $\beta$ cells in vivo. We generated mice deficient for ATG7 specifically in $\beta$ cells with hemizygous expression of h-IAPP. We crossed RIPCre Atg $7^{f / / f}$ mice (referred hereafter as $A t g 7^{4 \beta c e l l}$ mice) with homozygous h-IAPP transgenic mice to obtain 4 groups of mice: control, h-IAPP ${ }^{+/-}, A t g 7^{\Delta \beta c e l l}$, and h-IAPP ${ }^{+/-}: A t g 7^{\Delta \beta \text { cell }}$ mice. In both $A t g 7^{\Delta \beta c e l l}$ and h-IAPP ${ }^{+/-}: A \operatorname{tg} 7^{\Delta \beta c e l l}$ mice, we confirmed the specific knockout of ATG7 in $\beta$ cells by Western blot (Figure $5 \mathrm{~A}$ ). Reduction of autophagy in $A t g 7^{\Delta \beta c e l l}$ and h-IAPP ${ }^{+/}: A t g 7^{\Delta \beta c e l l}$ mice was confirmed by loss of the ATG7-mediated conversion of microtubule-associated protein 1 light chain-1 (LC3-I) to LC3-II required for formation of autophagosomes (ref. 25 and Figure 5A). Furthermore, deficiency in autophagy/lysosomal degradation was supported by accumulation of $\mathrm{p} 62$ in $A \operatorname{tg} 7^{\Delta \beta \text { cell }}$ and h-IAPP ${ }^{+/-}: \operatorname{Atg} 7^{\Delta \beta \text { cell }}$ mice (ref. 25 and Figure 5A). The higher molecular weight band indicative of tightly aggregated p62 (26) was increased in autophagy-deficient mice with h-IAPP expression compared with that in $A t g 7^{\Delta \beta c e l l}$ mice. Since our previous ex vivo data revealed that h-IAPP is targeted for p62-dependent lysosomal degradation, we hypothesized that deficiency in autophagy in h-IAPP-expressing $\beta$ cells might lead to h-IAPP accumulation and formation of toxic oligomers. The islet content of monomeric IAPP tended to be increased in $\mathrm{h}-\mathrm{IAPP}^{+/-}: \mathrm{Atg}^{\Delta / \beta \text { cell }}$ mice compared with that in control groups, even though the islet $\beta$ cell compliment in this model is decreased
(Supplemental Figure 11A). To detect toxic oligomers, we used the A11 antibody $(3,21)$. Although, we observed immunoreactivity for toxic oligomers in both h-IAPP ${ }^{+/-}$and h-IAPP ${ }^{+/-}: A \operatorname{tg} 7^{4 \beta \text { cell }}$ mice, the percentage of $\beta$ cells positive for A11 labeling was 5-fold higher in h-IAPP ${ }^{+-}:$Atg $^{7^{A \beta c e l l}}$ mice compared with that in h-IAPP ${ }^{+/}$mice (Figure 5B and Supplemental Figure 12A). A representative islet of a h-IAPP ${ }^{+/}:$Atg $^{4 / \beta c e l l}$ mouse with A11 labeling in $\beta$ cells is shown in Figure $5 \mathrm{C}$. Interestingly, $\beta$ cells containing p62-positive inclusions had less A11 labeling than cells without inclusions (Figure $5 \mathrm{~B}$ and Supplemental Figure 12B). These findings further support the hypothesis that $\mathrm{p} 62$ inclusions sequester h-IAPP from the intracellular compartments in which toxic oligomers (A11 binding) are prone to form (3). The conditions within the p62 inclusions apparently favor assembly of h-IAPP into relatively inert fibrils that are then presumably subject to lysosomal clearance over time if the autophagy/lysosomal pathway is functional.

Overall, these data show that autophagy deficiency results in increased levels of monomeric h-IAPP and toxic oligomers. These findings are consistent with an important role of the autophagy pathway in clearance of h-IAPP and thus protection of $\beta$ cells against h-IAPP toxicity.

Deficiency in autophagy leads to diabetes development and loss of $\beta$ cell mass due to increased $\beta$ cell apoptosis in human-IAPP transgenic mice. We further tested the postulate that autophagy is important in protecting $\beta$ cells against h-IAPP oligomer toxicity by evaluating diabetes development in autophagy-deficient h-IAPP transgenic 

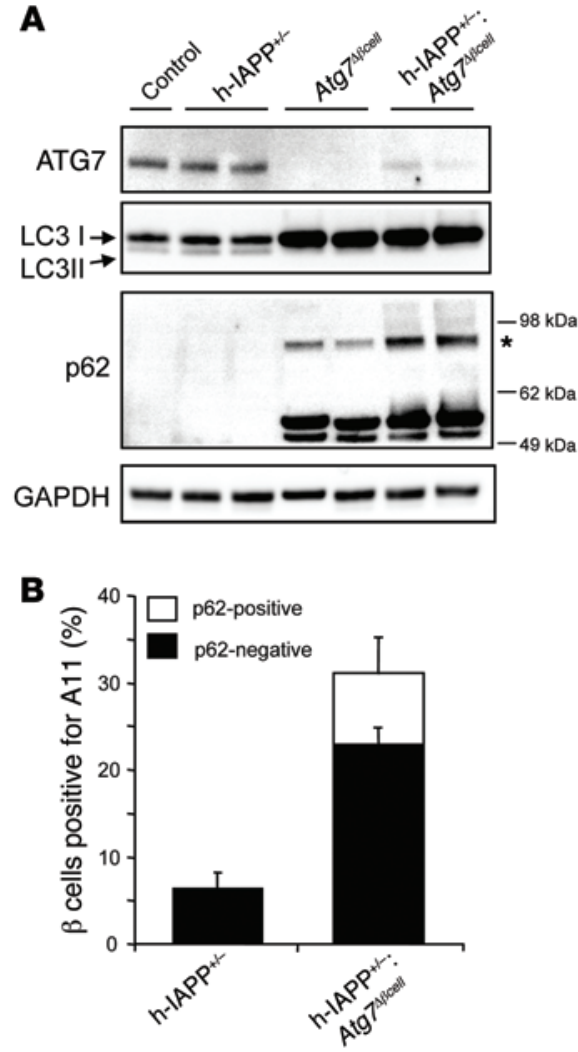

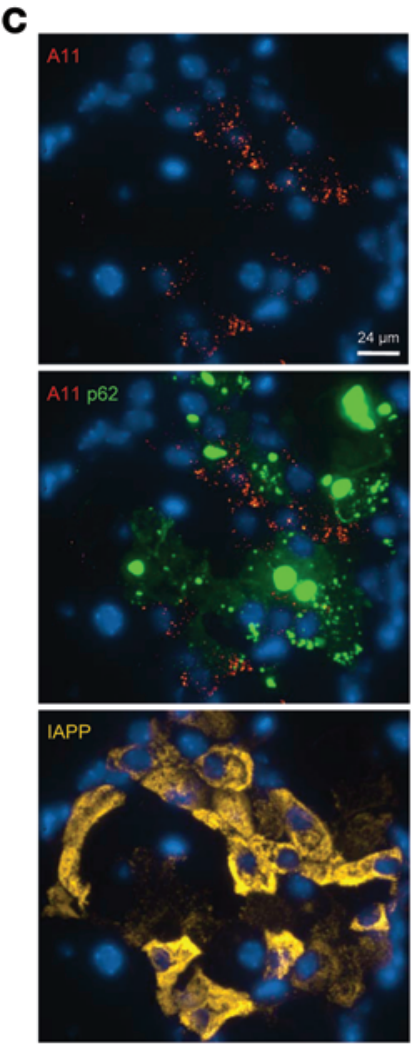

Figure 5. h-IAPP toxic oligomers accumulate in $\beta$ cells of hemizygous h-IAPP transgenic mice deficient in autophagy. (A) Protein levels of ATC7, LC3, and p62 were assessed by Western blot using islet protein lysates obtained from $\operatorname{Atg}^{1 / \beta c^{\text {cell }}}\left(9\right.$ weeks, $n=3$ ) mice and control, h-IAPP ${ }^{+/}$, and h-IAPP ${ }^{+-}$: Atg $7^{1 \beta \text { cell }}$ (all 9 weeks, $n=4$ ) mice. GAPDH was used as loading control. The asterisk indicates tightly aggregated p62. (B) Quantification of the percentage of $\beta$ cells positive for cytosolic A11 labeling in h-IAPP ${ }^{+/}:$Atg $7^{1 \beta \text { cell }}$ and $\mathrm{h}-\mathrm{APPP}^{+/-}$ mice. Included are the percentages of $\beta$ cells positive (white) or negative (black) for $p 62$ among A11-positive $\beta$ cells. Data are expressed as mean \pm SEM. (C) Confocal images of a representative islet from a h-|APPP ${ }^{+-}:$Atg $^{4 \beta c e l l}$ mouse pancreatic section stained with anti-oligomer antibody A11 (oligomers, red; p62, green; IAPP, yellow; nuclei, blue). Scale bar: $24 \mu \mathrm{m}$. mice. Fasting blood glucose was measured weekly, starting from 6 weeks of age, in all 4 groups of mice described above. Body weight remained comparable among groups (data not shown). As expected, fasting blood glucose concentrations were comparable in control and h-IAPP ${ }^{+/-}$mice throughout the study period. This confirms that mice hemizygous for $\beta$ cell transgenic expression of h-IAPP do not develop diabetes, presumably because their $\beta$ cells are competent to manage the resulting expression rate of amyloidogenic h-IAPP (27). Fasting blood glucose levels in $A t g 7^{\Delta \beta c e l l}$ mice were also comparable to those of control mice. In contrast, in h-IAPP ${ }^{+/-}: \operatorname{Atg}^{4 \beta \text { cell }}$ mice, fasting blood glucose increased relative to that of controls at 8 to 9 weeks of age $(97.9 \pm 7.0 \mathrm{mg} / \mathrm{dl}$ versus $70.4 \pm 2.7 \mathrm{mg} / \mathrm{dl}$ in h-IAPP ${ }^{+/-}$mice, $P<0.001$; Figure $\left.6 \mathrm{~A}\right)$. By 12 to 13 weeks of age, these mice had impaired fasting blood glucose $(123.7 \pm 11.4 \mathrm{mg} / \mathrm{dl}$ versus $73.4 \pm 3.0 \mathrm{mg} / \mathrm{dl}$ in h-IAPP ${ }^{+/-}$mice, $P<0.001$; Figure $6 \mathrm{~A}$ ), and by 14 to 15 weeks of age, h-IAPP ${ }^{+/-}:$Atg $^{4 / \beta c e l l}$ mice had diabetes $(178.3$ $\pm 65.6 \mathrm{mg} / \mathrm{dl}$ versus $74.6 \pm 3.3 \mathrm{mg} / \mathrm{dl}$ in $\mathrm{h}-\mathrm{IAPP}^{+/-}, P<0.001$; Figure 6A). Intraperitoneal glucose tolerance tests (IPGTTs) revealed glucose intolerance in 8-week-old h-IAPP ${ }^{+/-}: A t g 7^{4 \beta c e l l}$ mice before diabetes onset $\left(P<0.001\right.$ versus $A \operatorname{tg} 7^{A \beta c e l l}$ mice; $P<0.05$ versus h-IAPP ${ }^{+-}$mice; Figure $\left.6 \mathrm{~B}\right)$. In addition, serum insulin/glucose and C-peptide/glucose ratios (Figure 6, C and D) as well as islet and pancreatic insulin contents (Supplemental Figure 11B and Supplemental Figure 13) were decreased in h-IAPP ${ }^{+/}: A \operatorname{tg} 7^{4 \beta c e l l}$ mice, revealing defective insulin secretion. Consistent with the postulated protective action of autophagy against $\beta$ cell loss, $\beta$ cell mass was decreased in h-IAPP ${ }^{+/-}: A \operatorname{tg} 7^{\Delta \beta c e l l}$ mice compared with that in control groups $(P<0.05$; Figure 6E). The mechanism subserving the deficit in $\beta$ cell mass in h-IAPP ${ }^{+/-}:$Atg $^{4 \beta \text { cell }}$ mice was the increased $\beta$ cell apoptosis (2.5-fold versus h-IAPP ${ }^{+/-}$mice, $P<0.01$; Figure $6 \mathrm{~F}$ ).
These in vivo studies corroborate the in vitro data and reveal an important role for autophagy in protection of $\beta$ cells from toxicity of amyloidogenic h-IAPP, presumably by guarding against the formation and/or accumulation of toxic oligomers.

Oxidative damage and loss of a key antioxidant protective pathway in $\beta$ cells of autophagy-deficient mice that express oligomeric $h$-IAPP. Disruption of autophagy promotes oxidative stress (28), and $\beta$ cells are highly vulnerable to oxidative stress (29). We thus hypothesized that $\beta$ cells of mice deficient in autophagy that express h-IAPP would be characterized by increased oxidative stress as a contributing mechanism for apoptosis. To test this hypothesis, we evaluated $\beta$ cell levels of nitrotyrosine, an in situ marker for oxidative stress (30). Interestingly, p62 inclusions were positive for nitrotyrosine in $\beta$ cells of both $A t g 7^{\Delta \beta c e l l}$ and h-IAPP ${ }^{+-}: A t g 7^{4 \beta \text { cell }}$ mice (Supplemental Figure 14); however, cytosolic labeling for nitrotyrosine was more apparent in $\beta$ cells of h-IAPP ${ }^{+/}: \operatorname{Atg}^{4 / \beta c e l l}$ mice (Figure 7A). As shown in Figure 7B, the area positive for nitrotyrosine occupied $4.3 \% \pm 0.3 \%$ of the $\beta$ cell area in h-IAPP ${ }^{+/-}:$Atg $^{4 \beta \text { Bcell }}$ mice in comparison to $2.7 \% \pm 0.3 \%$ in Atg $7^{\Delta \beta \text { cell }}$ mice $(P<0.01)$, suggesting increased and more widespread oxidative damage.

The KEAP1-NRF2 system is one of the main cellular defense mechanisms against oxidative stress $(31,32)$. In unstressed conditions, the transcription factor nuclear factor erythroid 2-related factor 2 (NRF2) is constitutively degraded through the ubiquitin-proteasome system due to the action of its binding partner kelch-like ECH-associated protein 1 (KEAP1), an adaptor of the ubiquitin ligase complex. Autophagy deficiency leads to the formation of p62-positive inclusions that sequester KEAP1, thus preventing NRF2 ubiquitination. As a result, NRF2 becomes stabi- 

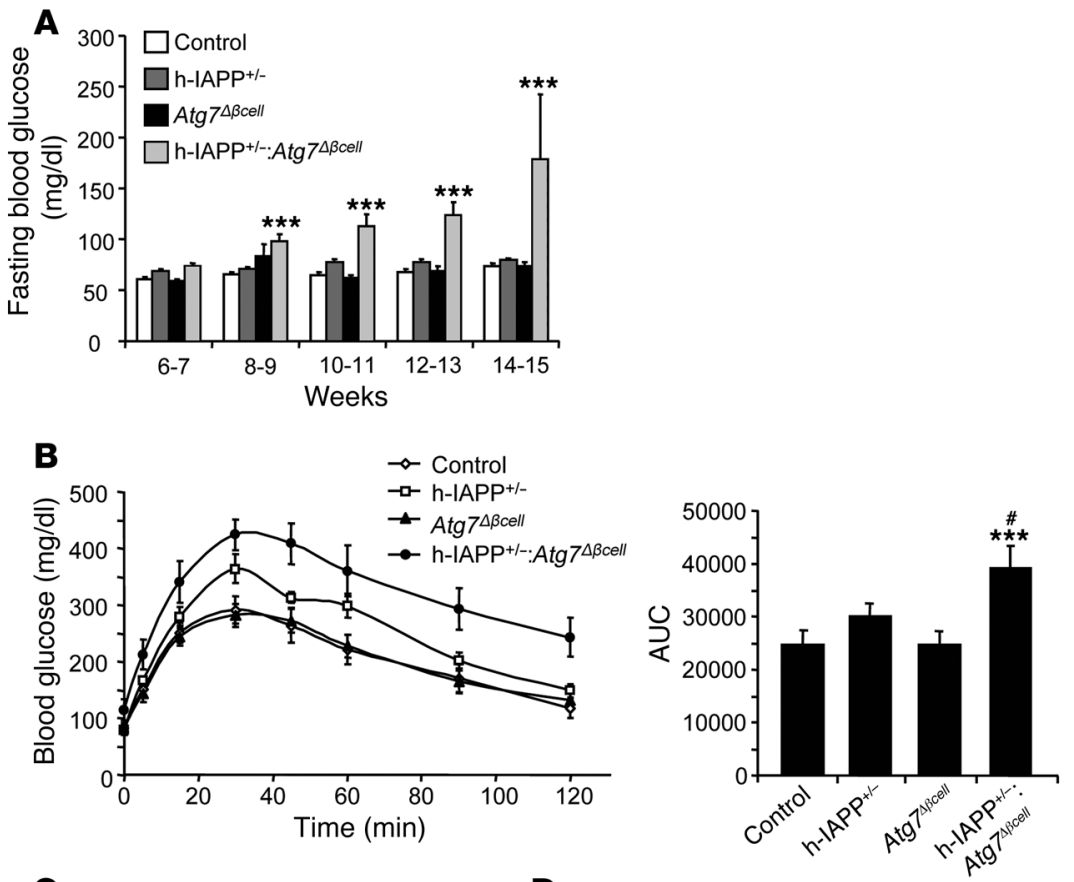

C
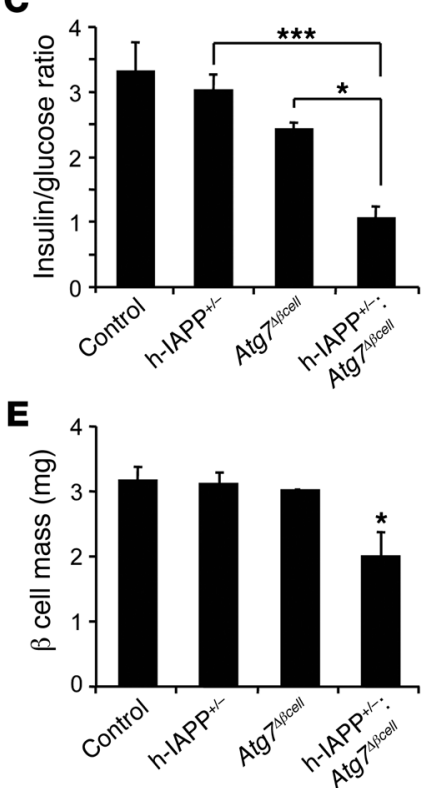

D

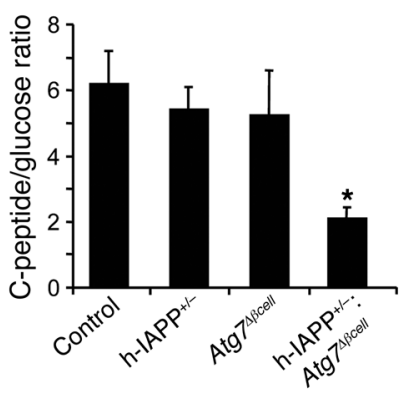

$\mathbf{F}$

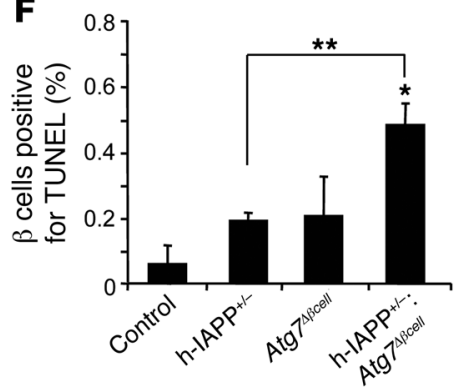

Figure 6. Deficiency in autophagy induces diabetes, impaired $\beta$ cell function, loss of $\beta$ cell mass, and increased $\beta$ cell apoptosis in hemizygous h-IAPP transgenic mice.

(A) Fasting blood glucose in control, h-IAPP ${ }^{+-}$, Atg $7^{\Delta / \beta c e l l}$, and h-IAPP ${ }^{+/}:$Atg $7^{\Delta \beta c e l l}$ mice. The number of mice per group of a given age is provided in Supplemental Table 1.

${ }^{* *} P<0.001$. (B) IPGTT performed by intraperitoneal injection of $2 \mathrm{~g} / \mathrm{kg}$ glucose in control and h-IAPP ${ }^{+/-}$: Atg $7^{\Delta \beta c e l l}$ mice (both 8 weeks, $n=6$ ) and $\mathrm{h}-\mathrm{IAPP}^{+/-}$and Atg $7^{A \beta c e l l}$ mice (both 8 weeks, $n=7$ ). The graph represents area under the curve (AUC). ${ }^{\#} P<0.05$, versus h-IAPP ${ }^{+/-}$ mice; ${ }^{* *} P<0.001$, versus $A t g 7^{A \beta c e l l}$ mice. (C) Plasma insulin/glucose ratio and (D) C-peptide/glucose ratio in control (14 \pm 1 weeks, $n=8)$, h-IAPP ${ }^{+/-}(14 \pm 1$ weeks, $n=8), \operatorname{Atg}^{\Delta \beta \text { cell }}(15$ weeks, $n=4)$, and h-IAPP ${ }^{+/-}:$Atg $^{\Delta \beta c e l l}$ (12 \pm 1 weeks, $n=6$ ) mice. ${ }^{*} P<0.05$, versus $A t g 7^{1 / \beta c e l l}$ and h-IAPP ${ }^{+/-}$mice for C-peptide/glucose ratio; ${ }^{* *} P<0.001$. (E) $\beta$ Cell mass in the 4 groups of mice at given mean age: control (14 \pm 1 weeks, $n=4)$, h-IAPP ${ }^{+/-}(14 \pm 1$ weeks, $n=4), \operatorname{Atg}^{1 \beta c e l l}(15$ weeks, $n=3)$, and $\mathrm{h}-\mid \mathrm{APP}^{+/-}: \operatorname{Atg}^{4 \beta c e l l}$ mice $(12 \pm 1$ weeks, $n=6)$. ${ }^{*} P<0.05$, versus all groups. (F) $\beta$ Cell apoptosis (TUNEL) in the 4 groups of mice at given mean age: control ( $13 \pm 1$ weeks, $n=3$ ), h-IAPP ${ }^{+/}$ ( $13 \pm 2$ weeks, $n=3$ ), Atg $7^{\Delta \beta \text { sell }}(15$ weeks, $n=3$ ), and h-IAPP ${ }^{+-}:$Atg $7^{1 / \beta c e l l}(12 \pm 1$ weeks, $n=3)$ mice. ${ }^{*} P<0.05$, versus Atg $7^{4 \beta c e l l}$ mice; ${ }^{* *} P<0.01$, versus $\mathrm{h}-\mathrm{IAPP}^{+/-}$mice. Data are expressed as mean \pm SEM lized and translocates to the nucleus to induce the transcription of numerous cytoprotective genes $(31,32)$.

Consistent with findings in autophagy-deficient hepatocytes (31), islets from $A t g 7^{\Delta \beta c e l l}$ mice showed an increase in NRF2 protein levels by Western blot (2.2-fold increase versus control mice, $P<0.05$; Figure 8A). In contrast, NRF2 levels failed to increase in islets of prediabetic h-IAPP ${ }^{+/-}:$Atg $^{\Delta \beta \text { cell }}$ mice compared with $A t g 7^{\Delta \beta c e l l}$ mice $(P<0.05$; Figure $8 \mathrm{~A})$. This was confirmed by immunofluorescence studies that revealed that h-IAPP ${ }^{+/}: A \operatorname{tg} 7^{A \beta c e l l}$ mice had decreased levels of nuclear and cytosolic NRF2 when compared with islets from $A t g 7^{\Delta \beta \text { cell }}$ mice (Figure 8, B and C). Interestingly, a certain amount of NRF2 was localized to p62-positive inclusions in both $A t g 7^{\Delta \beta c e l l}$ and h-IAPP ${ }^{+/-}:$Atg $7^{\Delta \beta c e l l}$ mice. This localization of NRF2 to p62-positive inclusions is not unexpected, since p62 sequesters homodimeric KEAP1 (data not shown), which can simultaneously interact with NRF2 (33). Consistent with the decrease in nuclear and cytosolic levels, NRF2 was also decreased in p62 inclusions of h-IAPP ${ }^{+/}: A t g 7^{\Delta \beta c e l l}$ mice in comparison with those of $A t g 7^{\Delta \beta c e l l}$ mice (Figure 8B). The lack of upregulation of the NRF2 transcription factor in prediabetic h-IAPP ${ }^{+-}: A t g 7^{\Delta \beta \text { cell }}$ mice points to a loss of protection against oxidative stress before diabetes onset.

To determine whether increased expression of h-IAPP in autophagy-deficient $\beta$ cells leads to either a general disruption of the antioxidative defense or a specific alteration of the NRF2 system, we evaluated mRNA levels of 2 antioxidant genes: glutathione S-transferase $\mu$ (Gstm1), a target of NRF2 (34), and Cu/Zn superoxide dismutase ( $\operatorname{Sod} 1)$, an antioxidant gene, which is not a primary target of NRF2 (35-37). $\beta$ Cells of Atg $7^{\Delta \beta c e l l}$ mice, which had an increase in NRF2 levels, displayed a corresponding increase in its target antioxidant gene, Gstm1 $(P<0.01$ versus control mice; 

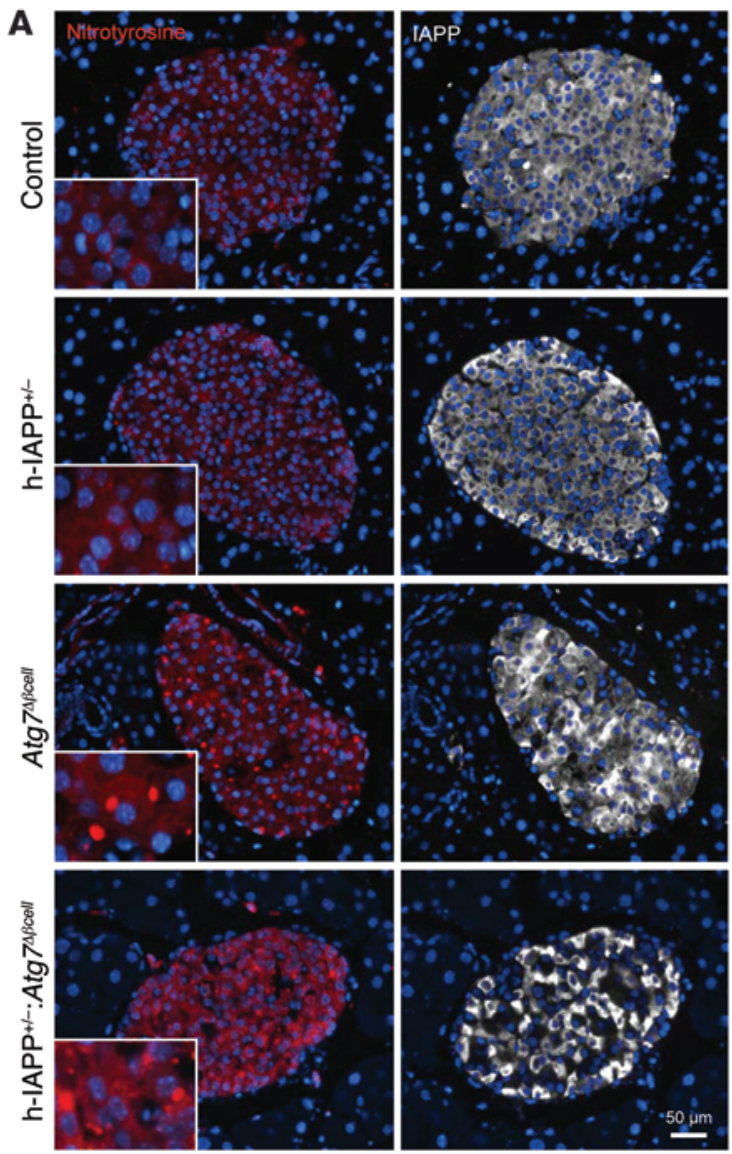

B

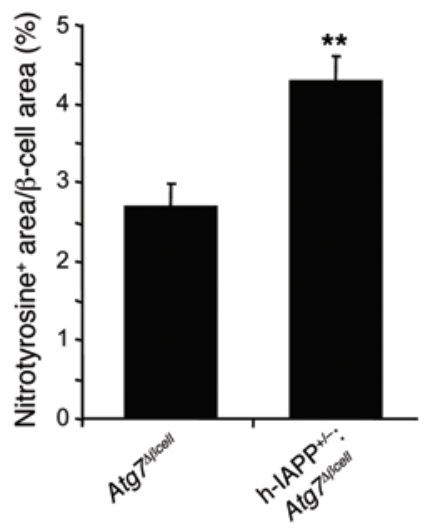

Figure 7. Deficiency in autophagy increases the oxidative damage in $\beta$ cells of hemizygous h-IAPP transgenic mice. (A) Nitrotyrosine levels were assessed by immunofluorescence in pancreatic tissue from control, h-IAPP ${ }^{+/-}$, Atg $^{A \beta B c e l l}$, and h-IAPP ${ }^{+/-}:$Atg $7^{\Delta \beta}$ cell mice (nitrotyrosine, red; IAPP, white; nuclei, blue). The insets show higher magnification. (B) Quantification of the fractional area of $\beta$ cell positive for nitrotyrosine (signal above background) in Atg $7^{A \beta c e l l}$ ( 15 weeks, $n=3$ ) and h-IAPP ${ }^{+-}:$Atg $7^{1 \beta \text { scell }}$ mice ( $12 \pm 1$ weeks, $n=3$ ) (expressed in percentage). 10-17 islets per section were analyzed. Data are expressed as mean \pm SEM; ${ }^{* *} P<0.01$. Scale bar: $50 \mu \mathrm{m}$.
Figure 9). Our data are in accordance with that from a previous publication reporting an increase in GST $\mu$ (Gstm genes) in $\beta$ cells of $A t g 7^{\Delta \beta c e l l}$ mice (9). In contrast, $\beta$ cells of h-IAPP ${ }^{+-}: A t g 7^{\Delta \beta c e l l}$ mice, which showed a cytosolic targeting of NRF2 and reduced NRF2 protein levels, failed to increase Gstm1 $\left(P<0.05\right.$ versus Atg $7^{\Delta \beta \text { cell }}$ mice; Figure 9). Interestingly, Sod1 was not similarly regulated (Figure 9). Altogether, these data suggest that increased expression of h-IAPP in autophagy-deficient $\beta$ cells does not lead to a general disruption of the antioxidative defense but rather specifically attenuates the NRF2-dependent protective mechanisms.

These data show that autophagy deficiency in the setting of expression of oligomeric IAPP leads to increased levels of oxidative damage in $\beta$ cells, most likely due to the failed compensatory increase in NRF2. The failed upregulation of this key transcription factor that is expected to protect against oxidative stress likely has deleterious consequences on $\beta$ cell survival.

\section{Discussion}

Autophagy is important for protection against h-IAPP toxicity. We report that autophagy plays a key role in protecting $\beta$ cells against oligomeric h-IAPP-induced toxicity. We identified the p62dependent lysosomal degradation as a mechanism responsible for IAPP clearance in $\beta$ cells and demonstrated that in vivo deficiency in autophagy, imposed on otherwise well-tolerated levels of h-IAPP expression in $\beta$ cells, induces diabetes with accumulation of IAPP toxic oligomers, impaired $\beta$ cell function, and increased apoptosis. We demonstrated that, in autophagy-deficient mice expressing oligomeric h-IAPP, the oxidative damage and loss of a key antioxidant protective pathway apparently contribute toward the increase in $\beta$ cell apoptosis. Interestingly, accumulation of autophagosomes and p62 (Supplemental Figure 15) as well as intracellular IAPP toxic oligomers has been observed in $\beta$ cells of humans with T2D $(3,38,39)$, suggesting that the autophagy system is activated but defective in T2D. The concept of an important role of autophagy to protect $\beta$ cells against accumulation of misfolded proteins is also supported by findings in the Akita mouse model of T2D, a model characterized by increased $\beta$ cell apoptosis induced by proinsulin misfolding. Stimulation of autophagy with rapamycin in the Akita mouse model decreased $\beta$ cell apoptosis and protected against diabetes (11). Collectively, these observations lend support to the concept that deficiency in the autophagy/ lysosomal pathway might contribute to misfolded proteins and toxic oligomer accumulation in human $\beta$ cells.

IAPP is degraded by the p62-dependent lysosomal pathway. Most aggregation-prone proteins are degraded by the autophagy pathway (40). In the present study, we show for the first time that IAPP is also cleared by the autophagy system in $\beta$ cells. We established that p62, by interacting with IAPP, is a mediator of lysosomal clearance of IAPP. The specificity of $\mathrm{p} 62$ to clearance of IAPP was highlighted by the absence of p62 binding to the more abundantly expressed $\beta$ cell secretory protein, insulin. p62 contains several interaction protein domains, among which the ubiquitin binding domain (UBA) is important for targeting ubiquitinated proteins to autophagic clearance (41). In our study, we found that IAPP is 
A
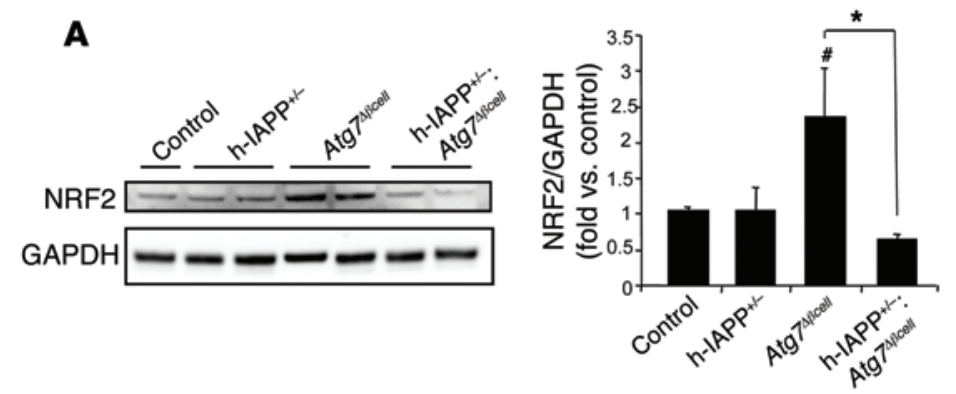

B
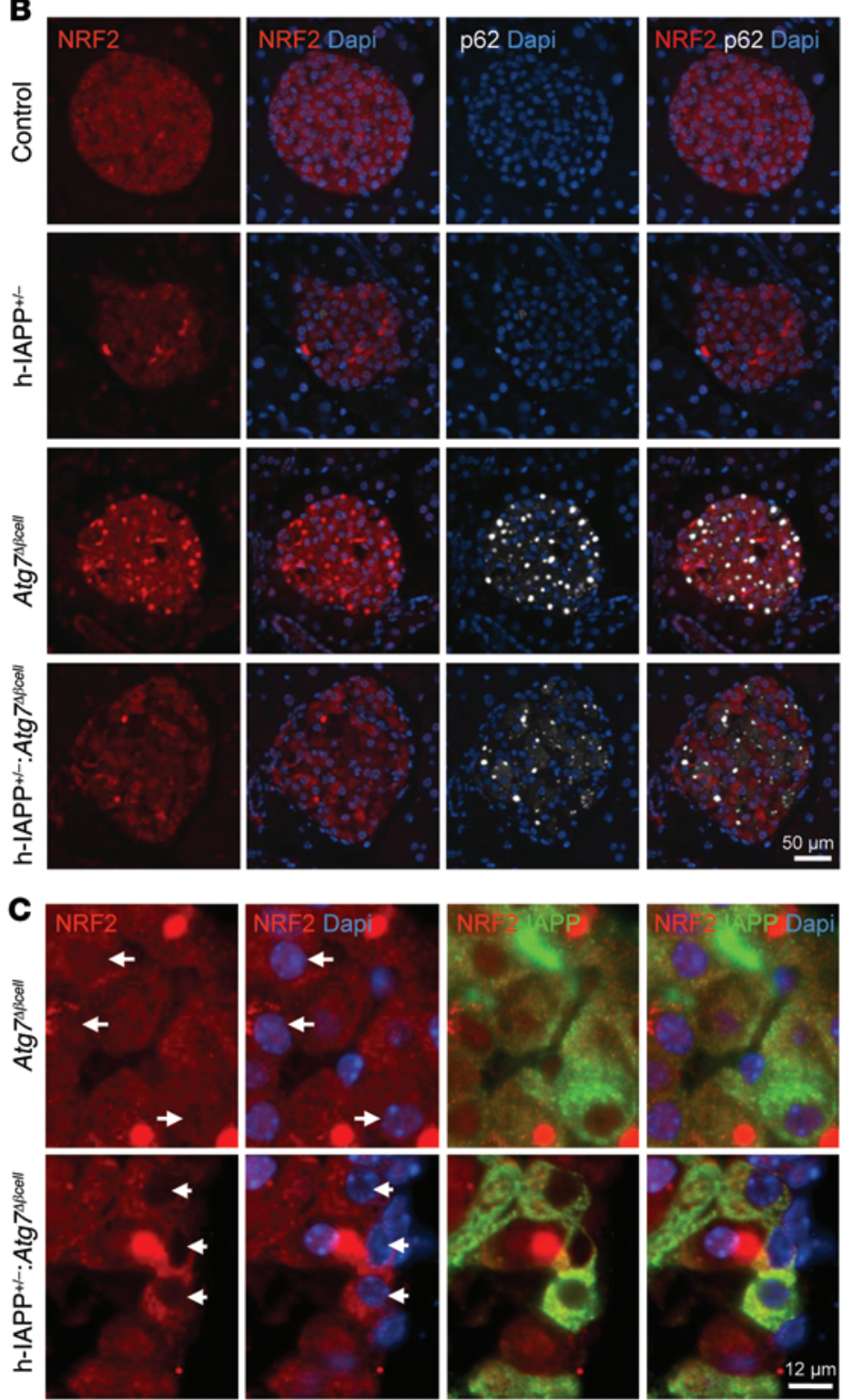

Figure 8. Antioxidant NRF2 is reduced in hemizygous h-IAPP transgenic mice deficient in autophagy. (A) Protein levels of NRF2 were assessed by Western blot using islet lysates obtained from control ( 9 weeks, $n=3$ ), h-IAPP ${ }^{+/-}$(9 weeks, $n=3$ ), Atg $7^{A \beta c e l l}$ (9 weeks, $n=3$ ), and h-IAPP ${ }^{+/}:$Atg $7^{\Delta \beta \text { isell }}$ mice (9 weeks, $n=3$ ). GAPDH was used as loading control. The graph represents the quantification of NRF2 protein levels. Data are expressed as mean \pm SEM; ${ }^{*} P<0.05$; ${ }^{*} P<0.05$, versus control and h-IAPP ${ }^{+/}$ mice. (B) NRF2 and p62 levels were assessed by immunofluorescence in pancreatic sections from control, h-IAPP ${ }^{+/}$, Atg $^{4 \Delta s c e l l}$, and h-IAPP ${ }^{+-}:$Atg $7^{1 \beta \text { cell }}$ mice (NRF2, red; p62, white; nuclei, blue). Scale bar: $50 \mu \mathrm{m}$. (C) Images of islets from $A t g 7^{4 \beta c e l l}$ and $\mathrm{h}-\mid \mathrm{APP}+/-$ Atg $^{4 \beta \mathrm{Bcell}}$ mice showing cytosolic and nuclear staining of NRF2 (NRF2, red; IAPP, green; nuclei, blue). Arrows indicate nuclei. Scale bar: $12 \mu \mathrm{m}$.

that extracellular amyloid derived from IAPP in humans and h-IAPP transgenic rodents is immunoreactive for ubiquitin (42), implying that extracellular islet amyloid in T2D may originate intracellularly.

Our data show that autophagy is important in IAPP homeostasis and hint at which species of IAPP, including unprocessed IAPP, monomers, toxic oligomers, or fibrillar inclusions, are the preferred targets of autophagy. We show that p62 interacts with monomeric IAPP and targets it for degradation by autophagy. Notably, our data suggest that h-IAPP sequestered by p62 reaches a saturation threshold at which it will be stabilized as amyloid fibrils and form inclusions. However, our experiments do not allow us to determine the sequence of events involved in the interaction between h-IAPP and p62. Thus, we cannot exclude the possibility that p62 interacts initially with fibrillar IAPP and then forms inclusions. We propose that these cytoplasmic inclusions with p62 at their core sequester oligomerization-prone h-IAPP in its less toxic fibrillar form, which may serve as a buffer to protect $\beta$ cells against proteotoxicity and dysfunction caused by h-IAPP. Ultimately, these p62 inclusions must be removed and degraded by the autophagy/lysosome pathway for $\beta$ cells to remain protected, as described for $\alpha$-synuclein- or huntingtin-containing p62 inclusions in neurons $(43,44)$.

Supporting that hypothesis, we found that autophagydeficient mice expressing h-IAPP contain fewer toxic oligomers in $\beta$ cells with $\mathrm{p} 62$ inclusions than in those without $\mathrm{p} 62$ inclusions. The notion that inclusions of $\mathrm{p} 62$ serve a protective role is in accordance with previous studies in the field of neurodegenerative diseases, such as Huntington's disease, in which $\mathrm{p} 62$ inclusions are protective against huntingtin-induced cell death (43). Furthermore, p62 may mediate protection of $\beta$ cells by other mecha-

polyubiquitinated. We can thus speculate that this posttranslational modification of IAPP would allow its binding to the UBA domain of p62. However, since polyubiquitinated IAPP represents only a modest fraction of the total IAPP content, other domains of p62 or other intermediate proteins may be involved in the p62IAPP interaction. Furthermore, due to the oligomeric property of IAPP, polyubiquitinated IAPP may attract other unmodified IAPP to the scaffold protein $\mathrm{p} 62$. Interestingly, we reported previously nisms responsible for removal of oligomeric-prone proteins. One such mechanism may be the increased extrusion of IAPP by the exosome machinery (45) under conditions of autophagy inhibition, as described recently for $\alpha$-synuclein (46). Although we propose that p62 may have a protective role in $\beta$ cells expressing h-IAPP, we can surmise that the excessive accumulation of $\mathrm{p} 62$ inclusions cannot afford an unlimited protective capacity against formation of toxic IAPP oligomers. Indeed, given the important roles of p62 in 


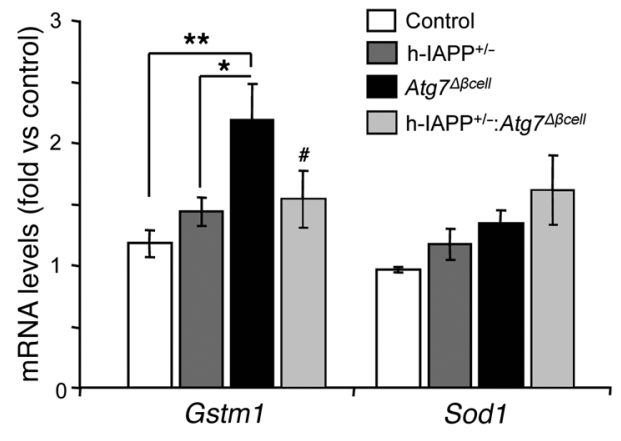

other signaling pathways, it might be predicted that such sustained diversion of p62 is detrimental to cell function and viability.

Oxidative stress is a contributing mechanism for h-IAPP toxicity in autophagy-deficient conditions. Although increased oxidative damage in $\beta$ cells from Atg $7^{A \beta c e l l}$ mice was reported previously (28), we identified here a compensatory mechanism aimed to protect $\beta$ cells from the deleterious effects of oxidative stress. Indeed, we found that $\beta$ cells from $A t g 7^{4 \beta \text { scel }}$ mice show an increase in the transcription factor NRF2, which is crucial for the expression of antioxidant and detoxifying enzymes (31). These findings provide a mechanism for the increased expression of detoxifying enzymes, such as GST $\mu$ and GST $\theta$, in $\beta$ cell-specific autophagy-deficient mice (9) and may explain why these mice do not develop overt diabetes but rather glucose intolerance (9). In contrast, we found that $\beta$ cells of mice deficient in autophagy and expressing the oligomerization-prone h-IAPP further accumulate oxidative damage that is not compensated by increased NRF2 levels. Given the important role of NRF2 in protection of $\beta$ cells against stress conditions and death (47-49), the alteration of the compensatory increase in NRF2 may contribute to diabetes onset in these mice. The mechanism of failed NRF2 availability in pancreatic islets in the context of concurrent expression of amyloidogenic IAPP and deficiency of autophagy remains to be elucidated. Although NRF2 plays a pivotal role in expression of antioxidant enzymes, the removal of damaged mitochondria (mitophagy) is also a key mechanism to prevent the formation of reactive oxygen species (50). We can thus speculate that h-IAPP-damaged mitochondria (3) accumulate in $\beta$ cells of h-IAPP ${ }^{+/}:$Atg $^{\text {As cell }}$ mice due to defective mitophagy and likely contribute to oxidative damage and $\beta$ cell deficit.

Concluding remarks. Oligomerization-prone IAPP is not only targeted for autophagy/lysosomal degradation but also influences the autophagy pathway (15), leading to an adverse cycle that results in increased levels of toxic h-IAPP oligomers and deficient autophagy. This is the first line of evidence establishing a protective role of autophagy against h-IAPP-induced toxicity in $\beta$ cells, which implicates the players of the autophagy pathway as key therapeutic targets for treatment and prevention of T2D.

\section{Methods}

\section{Rodent models}

Rats and mice were bred and housed at the UCLA animal housing facility. The Office of Animal Research Oversight at UCLA approved all experimental procedures. Animals were maintained on a 12-hour-
Figure 9. mRNA levels of the antioxidant genes Gstm1 and Sod1 in islets from hemizygous h-IAPP transgenic mice deficient in autophagy. Levels of Gstm1 and Sod1 mRNA were evaluated by RT-qPCR in islets isolated from control (9 weeks, $n=4$ ), h-IAPP ${ }^{+/-}$(9 weeks, $n=3$ ), Atg $7^{A \beta c e l l}$ (9 weeks, $n=3$ ), and h-|APP ${ }^{+/-}: A t g 7^{\Delta \beta c e l l}(9$ weeks, $n=3$ ) mice. Cyclophilin was used as housekeeping gene. Data are expressed as mean $\pm \mathrm{SEM}$; ${ }^{*} P<0.05$; ${ }^{* *} P<0.01 ;{ }^{\#} P<0.05$, versus Atg $7^{A \beta c e l l}$ mice.

day/night cycle, with Harlan Teklad Rodent Diet 8604 and water ad libitum. Male mice were used for the experiments.

Rats. The generation of HIP rats has been described in detail previously (4). In this study, we used 4- to 6-month-old WT and prediabetic HIP rats.

Mice. The generation and characterization of h-TG mice [FVB$\mathrm{Tg}(\mathrm{IAPP}) 6 \mathrm{Jdm} / \mathrm{Tg}(\mathrm{IAPP}) 6 \mathrm{Jdm}]$ and $\mathrm{r}-\mathrm{TG} \quad[\mathrm{FVB} / \mathrm{N}-\mathrm{Tg}(\mathrm{Iapp}) 6 \mathrm{Wcs} / \mathrm{Tg}$ (Iapp)6Wcs] have been described previously (6). Control FVB mice were originally purchased from Charles Rivers Laboratory and bred at UCLA. $\operatorname{Atg} 7^{A / f l}$ mice were acquired from Masaaki Komatsu (Protein Metabolism Project, Tokyo Metropolitan Institute of Medical Science, Tokyo, Japan), and their generation is explained in detail elsewhere (51). RIP-Cre mice expressing Cre-recombinase under the rat insulin promoter were described previously (52). Atg $7^{f / f l}$ mice and RIP-Cre mice were bred to generate $A t g 7^{4 \beta \text { cell }}$ mice (on B6 background), which were then bred to homozygous h-IAPP transgenic mice (h-TG mice, on FVB background). The siblings from the first generation were bred to each other to generate the 4 working groups: control, h-IAPP ${ }^{+/-}$(hemizygous h-IAPP transgenic mice), Atg $7^{\Delta \beta c e l l}$, and h-IAPP ${ }^{+/-}: A t g 7^{\Delta \beta c e l l}$ (hemizygous h-IAPP transgenic mice:Atg $\left.7^{\Delta \beta c e l}\right)$. Mice deficient for p62 ( $p 62^{---}$mice) were acquired from Tetsuro Ishii (University of Tsukuba, Ibaraki, Japan), and their generation is explained in detail elsewhere (53).

\section{Metabolic analysis}

Fasting body weight and blood glucose values were obtained in the morning after an overnight fast (clean cages and bedding, no food, water ad libitum). Blood glucose values were measured on a tail-tip blood sample with a FreeStyle Freedom Lite Glucometer (Abbott). The pancreases were then rapidly dissected from euthanized animals for morphologic studies (see below). For h-IAPP ${ }^{+/}: A \operatorname{tg} 7^{\Delta \beta c e l l}$ and corresponding control mice, fasting blood glucose was measured weekly between 6 and 15 weeks of age. Pancreata were collected at diabetes development or 15 weeks of age, which ever came first. Controls were age matched. Blood was collected from fasted mice at time of euthanasia. Serum insulin and C-peptide were measured using competitive ELISA (mouse insulin ELISA, Mercodia, 10-1247-01; mouse C-peptide ELISA, Alpco, 80-CPTMS-E01).

For determination of mouse pancreatic insulin content, the head of the pancreas was isolated and weighed. $20 \mu \mathrm{l}$ acid-ethanol $(0.18 \mathrm{~N}$ $\mathrm{HCl}$ in $70 \%$ ethanol) per mg of pancreas was added to the tissue. Tissue was homogenized using Tissuelyser II (Qiagen). Homogenate was incubated overnight at $4^{\circ} \mathrm{C}$ and then centrifuged at $425 \mathrm{~g}$ for 15 minutes at $4^{\circ} \mathrm{C}$. The supernatant was collected, and insulin content was measured using competitive ELISA (mouse insulin ELISA, Mercodia, 10-1247-01). 
A glucose tolerance test (IPGTT) was performed on 8-week-old mice after an overnight fast. Blood glucose was measured before intraperitoneal injection of glucose $(2 \mathrm{~g} / \mathrm{kg}$ body weight) and then 5 , $15,30,45,60,90$, and 120 minutes after injection.

\section{Islet isolation}

After an overnight fast, animals were euthanized using isoflurane. The bile duct was clamped at the entrance to duodenum and cannulated, and the pancreas was perfused with $2 \mathrm{ml}$ collagenase solution (HBSS [Invitrogen, 14065] supplemented with $25 \mathrm{mM}$ HEPES [Invitrogen, 15630], $0.23 \mathrm{mg} / \mathrm{ml}$ liberase [Roche, 05401020001], and $0.1 \mathrm{mg} / \mathrm{ml}$ DNase [Roche, 10104159001]). Pancreas was removed, transferred into a glass vial containing $2 \mathrm{ml}$ ice-cold collagenase solution, digested for 19 minutes at $37^{\circ} \mathrm{C}$, and then dispersed by shaking for 30 seconds. Islets were manually picked, washed with ice-cold PBS, and lysed in NP4O lysis buffer (0.5\% Nonidet P-40, 20 mM Tris-HCl, pH 7.5, $150 \mathrm{mM} \mathrm{NaCl}, 2 \mathrm{mM} \mathrm{MgCl}$, $1 \mathrm{mM}$ dithiothreitol, $5 \mathrm{mM} \mathrm{NaF}, 1 \mathrm{mM}$ $\mathrm{Na}_{3} \mathrm{VO}_{4}$, and protease inhibitors [Sigma-Aldrich]). After 10 minutes incubation in lysis buffer on ice, islets were sonicated for 10 seconds and centrifuged at 10,621 $g$ at $4^{\circ} \mathrm{C}$ for 10 minutes. Supernatant was stored at $-20^{\circ} \mathrm{C}$ until use for subsequent analysis. Dissolution of the detergent-resistant pellets from HIP rat islets and fractionation by HPLC was performed according to Shaw BF, et al. (20).

\section{Human islets}

Human islets were obtained from the Integrated Islet Distribution Program (http://iidp.coh.org). The islet purity was 90\%-95\%, as assessed by dithizone staining. Islets were obtained from 4 heart-beating organ donors, and none had a previous history of diabetes or metabolic disorders. Islet viability was assessed by the Live/ Dead Kit (Molecular Probes, L-3224).

\section{Cell culture}

The rat insulinoma cell line INS 832/13 was provided by Christopher B. Newgard (Duke University School of Medicine, Durham, North Carolina, USA) (54). INS 832/13 cells were grown in RPMI-1640 medium supplemented with $10 \mathrm{mM}$ HEPES, $1 \mathrm{mM}$ sodium pyruvate, $100 \mathrm{IU} / \mathrm{ml}$ penicillin and $100 \mathrm{mg} / \mathrm{ml}$ streptomycin (Invitrogen), 10\% heat-inactivated FBS (Gemini), and $50 \mathrm{mM} \beta$-mercaptoethanol (Sigma-Aldrich) at $37^{\circ} \mathrm{C}$ in a humidified $5 \% \mathrm{CO}_{2}$ atmosphere.

For adenovirus transduction experiments, INS 832/13 cells were plated on 6-well plates at a density of $10^{6}$ cells per well and cultured for 24 hours. Cells were transduced with r-IAPP or h-IAPP adenoviruses at $400 \mathrm{MOI}$ in complete RPMI medium for the indicated time. The generation and use of p62/control shRNA lentiviruses were described in detail in Rivera et al. (15).

Rapamycin, E-64-d, and pepstatin A were purchased from Sigma-Aldrich. At the end of the experiment, cells were washed with cold PBS and lysed for 10 minutes at $4^{\circ} \mathrm{C}$ in NP-40 lysis buffer and centrifuged at $10,621 \mathrm{~g}$ for 10 minutes to remove insoluble materials. Supernatant was stored at $-20^{\circ} \mathrm{C}$ until use for subsequent protein determination by BCA assay (Bio-Rad, 500-0112) and Western blotting.

\section{Immunoprecipitation}

INS 832/13 cell lysates or mouse islet lysates were incubated with rabbit anti-p62 antibody (MBL, PM045). Immunocomplexes were precipitated from the supernatant using the Dynabeads Protein A
Immunoprecipitation Kit (Invitrogen, 100-06D) according to the manufacturer's instructions, boiled in sample buffer, resolved by SDSPAGE, and immunoblotted with appropriate antibodies. Similar immunoprecipitation experiments were performed using soluble and insoluble fractions prepared from mouse islets using the ReadyPrep Protein Extraction Kit (Soluble/Insoluble) (Bio-Rad, 163-2085) according to the manufacturer's instructions.

Rat islet lysates were solubilized in SDS lysis buffer (1\% SDS, 5 mM EDTA, 10 mM DTT, protease inhibitors [Sigma-Aldrich]). After sonication for 10 seconds, lysates were boiled for 10 minutes and centrifuged at 20,817 $g$ for 1 minute. Supernatants were incubated with rabbit anti-IAPP antibody (25-37 aa; Bachem, T-4157). Immunocomplexes were precipitated from the supernatant with protein $A / G$ plus agarose (Calbiochem, IP05), washed 3 times with ice-cold PBS, boiled in sample buffer, and analyzed by Western blotting using a mouse anti-ubiquitin antibody (clone FK2, Biomol, PW8810-0500).

\section{Western blotting}

Proteins (25-50 $\mu$ g per lane) were separated on a $4 \%-12 \%$ Bis-Tris NuPAGE gel (Invitrogen) and blotted onto a PVDF membrane (FluoroTrans; VWR, 29301856). Membranes were probed overnight at $4^{\circ} \mathrm{C}$ with primary antibodies against ATG7 (Cell Signaling Technology, 2631S), LC3B (Cell Signaling Technology, 2775S), p62 (Progen Biotechnik, GP62-C), GAPDH (Cell Signaling Technology, 2118S), insulin (Cell Signaling Technology, 3014S), IAPP (25-37 aa; Bachem, T-4157), Ubiquitin (clone FK2, Biomol, PW8810-0500), cleaved caspase-3 (Cell Signaling Technology, 9661S), and NRF2 (Santa Cruz, sc-13032). Horseradish peroxidase-conjugated secondary antibodies were from Invitrogen. Proteins were visualized by enhanced chemiluminescence (Millipore, WBKLS0500), and protein expression levels were quantified using the Labworks software (UVP).

\section{RNA isolation, RT-PCR, and real-time quantitative PCR}

Total RNA was extracted using the RNeasy Mini Kit (Qiagen) performing on-column DNase digestion with RNase-Free DNase Set (Qiagen), according to the manufacturer's instructions. $0.25 \mu \mathrm{g}$ RNA was used for preparation of single-stranded cDNA using Superscript III Reverse Transcriptase (Invitrogen) by the oligo-dT priming method. Real-time quantitative PCR was performed using the

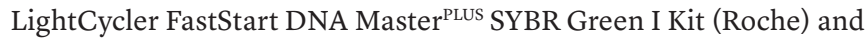
the LightCycler PCR equipment (Roche) (or the Fast SYBR Green Master Mix and the 7900HT Fast Real-Time PCR System [Applied Biosystems]). The oligonucleotide primers were: 5'-GAGAGCTACACCTGTCGGAAG-3' + 5'-AGTTTGCCAGACGTTGTGT-3' for rat IAPP, 5'-GCAGCTCATCATGCTCTGTTA-3' + 5'-TTTCTCAGGGATGGTCTTCAA-3' for mouse Gstm1, and 5'-CAGGACCTCATTTTAATCCTCAC-3' + 5'-TGCCCAGGTCTCCAACAT-3' for mouse Sod1. Measurements were normalized to the housekeeping genes Gapdh or cyclophilin.

\section{Immunohistochemistry and immunofluorescence}

Pancreata were fixed in $4 \%$ paraformaldehyde for 24 hours at $4^{\circ} \mathrm{C}$ and embedded in paraffin. Four- $\mu \mathrm{m}$ sections of pancreas were then taken through the fixed tissue in the plane of embedding so that a near-complete section of pancreas (head, body, and tail) was obtained with each section. Sections were stained as described previously (7). Frozen sections (used for thioflavine S and A11 staining) were prepared 
from $4 \%$ paraformaldehyde-fixed tissue embedded in optimal cutting temperature compound (OCT).

$\beta$ Cell mass. Pancreatic sections were stained for insulin and hematoxylin/eosin. The $\beta$ cell mass was measured by first quantifying the fraction of pancreatic cross-sectional area positive for insulin and multiplying this by the pancreatic weight.

$\beta$ Cell apoptosis. Sections were costained by immunofluorescence for TUNEL (Roche, 12156792910) and insulin. At least 20 islets per animal (with a minimum of $20 \beta$ cells per islet in plane of section) were examined in detail for the total number of TUNEL-positive $\beta$ cells. The frequency of TUNEL was presented as the percentage of stained $\beta$ cells among the total number of $\beta$ cells.

Antibodies and staining. Sections were stained using antibodies against p62 (Progen Biotechnik, GP62-C, 1:400), NRF2 (Santa Cruz, sc-13032, 1:50), IAPP (Genway, 20-272-190339), IAPP (Bachem, T-4157), Nitrotyrosine (Millipore, AB5411), Nkx6.1 (Developmental Studies Hybridoma Bank, F55A10), CD11b/c (Abcam, ab1211), and insulin (Invitrogen, 18-0067). IAPP antibodies stain monomeric IAPP in intracellular insulin granules but do not allow detection of IAPP fibrils or oligomers in which the antibody epitope is not accessible. For thioflavin S staining (IAPP fibrils), frozen sections were incubated in $0.1 \%$ thioflavin S (Sigma-Aldrich, R311820) for 10 minutes at room temperature, washed 2 times with $70 \%$ ethanol, once with $95 \%$ ethanol, and 3 times with exchanges of distilled water before antibody incubations. We ensured that thioflavin S staining did not bleed over across filters by imaging thioflavin S-positive area with other filter cubes. For oligomer staining, frozen sections were incubated overnight at $4^{\circ} \mathrm{C}$ with $\mathrm{A} 11$ antibody (gift from Charles Glabe, University of California, Irvine, Irvine, California, USA), anti-p62 antibody, or anti-IAPP antibody on consecutive nights. Antibodies were diluted 1:100 unless specified otherwise. Slides were mounted with Vec- tashield with DAPI (Vector Laboratories, H-1200) and viewed using a Leica DM6000 microscope (Leica Microsystems). Images were acquired using Openlab software (Improvision).

\section{Statistics}

Results are expressed as the mean \pm SEM for $n$ independent experiments, as indicated in figure legends. Statistical analyses were carried out by 2-tailed Student's $t$ test or ANOVA, followed by Fisher's posthoc test for multiple comparisons using Statistica (Statsoft). A $P$ value of less than 0.05 was taken as evidence of statistical significance.

\section{Acknowledgments}

These studies were supported by grants from National Institute of Diabetes and Digestive and Kidney Diseases (DK059579 to P.C. Butler and DK090995 to J.F. Rivera), NIH (AG033069 to C.G. Glabe), the Larry L. Hillblom Foundation (2012-D-001-SUP to S. Costes, 2007-D-003-NET to P.C. Butler), and the Esther B. O'Keeffe Foundation. We thank Anil Bhushan for providing the RIP-Cre mice. We thank UCLA CURE Vector Core (NIH 2P30DK04301)/JCCC Vector Shared Resources facility (NIH: CA-016042) for the generation of shRNA lentivirus. We thank Julian P. Whitelegge for his help with HPLC fractionation. We thank Chang Liu and Rosibel Hernandez for their excellent technical help. We thank Rogelio Pinon, Rasika Deshpande, and Mark Murata for their participation in data analysis.

Address correspondence to: Peter C. Butler, Larry Hillblom Islet Research Center, David Geffen School of Medicine, UCLA, 900 Veteran Ave., 24-130 Warren Hall, Los Angeles, California 90095-7073, USA. Phone: 310.794.7645; E-mail: pbutler@ mednet.ucla.edu.
1. Butler AE, Janson J, Bonner-Weir S, Ritzel R, Rizza RA, Butler PC. $\beta$-Cell deficit and increased $\beta$-cell apoptosis in humans with type 2 diabetes. Diabetes. 2003;52(1):102-110.

2. Haataja L, Gurlo T, Huang CJ, Butler PC. Islet amyloid in type 2 diabetes, and the toxic oligomer hypothesis. Endocr Rev. 2008;29(3):303-316.

3. Gurlo T, et al. Evidence for proteotoxicity in $\beta$ cells in type 2 diabetes: toxic islet amyloid polypeptide oligomers form intracellularly in the secretory pathway. Am J Pathol. 2010;176(2):861-869.

4. Butler AE, Jang J, Gurlo T, Carty MD, Soeller WC, Butler PC. Diabetes due to a progressive defect in $\beta$-cell mass in rats transgenic for human islet amyloid polypeptide (HIP rat) - a new model for type 2 diabetes. Diabetes. 2004;53(6):1509-1516.

5. Hoppener JWM, et al. Extensive islet amyloid formation is induced by development of type II diabetes mellitus and contributes to its progression: pathogenesis of diabetes in a mouse model. Diabetologia. 1999;42(4):427-434.

6 . Huang CJ, et al. Induction of endoplasmic reticulum stress-induced $\beta$-cell apoptosis and accumulation of polyubiquitinated proteins by human islet amyloid polypeptide. Am J Physiol Endocrinol Metab. 2007;293(6):E1656-E1662.

7. Huang CJ, et al. High expression rates of human islet amyloid polypeptide induce endoplasmic reticulum stress-mediated $\beta$-cell apoptosis, a characteristic of humans with type 2 but not type 1 diabetes. Diabetes. 2007;56(8):2016-2027.

8. Kirkin V, McEwan DG, Novak I, Dikic I. A role for ubiquitin in selective autophagy. Mol Cell. 2009;34(3):259-269.

9. Ebato C, et al. Autophagy is important in islet homeostasis and compensatory increase of $\beta$ cell mass in response to high-fat diet. Cell Metab. 2008;8(4):325-332.

10. Jung HS, et al. Loss of autophagy diminishes pancreatic $\beta$ cell mass and function with resultant hyperglycemia. Cell Metab. 2008;8(4):318-324.

11. Bachar-Wikstrom E, et al. Stimulation of autophagy improves endoplasmic reticulum stressinduced diabetes. Diabetes. 2013;62(4):1227-1237.

12. Mulder H, Ahren B, Stridsberg M, Sundler F. Non-parallelism of islet amyloid polypeptide (amylin) and insulin gene expression in rats islets following dexamethasone treatment. Diabetologia. 1995;38(4):395-402.

13. Cuervo AM, Bergamini E, Brunk UT, Droge W, Ffrench M, Terman A. Autophagy and aging: the importance of maintaining "clean" cells. Autophagy. 2005;1(3):131-140.

14. Koga H, Kaushik S, Cuervo AM. Protein homeostasis and aging: The importance of exquisite quality control. Ageing Res Rev. 2011;10(2):205-215.
15. Rivera JF, et al. Human-IAPP disrupts the autophagy/lysosomal pathway in pancreatic $\beta$-cells: protective role of p62-positive cytoplasmic inclusions. Cell Death Differ. 2011;18(3):415-426.

16. Zhang L, et al. Small molecule regulators of autophagy identified by an image-based high-throughput screen. Proc Natl Acad Sci U S A. 2007;104(48):19023-19028.

17. Costes $S$, et al. $\beta$-Cell dysfunctional ERAD/ubiquitin/proteasome system in type 2 diabetes mediated by islet amyloid polypeptide-induced UCHL1 deficiency. Diabetes. 2011;60(1):227-238.

18. Daval M, Gurlo T, Costes S, Huang CJ, Butler PC. Cyclin-dependent kinase 5 promotes pancreatic $\beta$-cell survival via Fak-Akt signaling pathways. Diabetes. 2011;60(4):1186-1197.

19. Huang CJ, et al. Calcium-activated calpain-2 is a mediator of $\beta$ cell dysfunction and apoptosis in type 2 diabetes. J Biol Chem. 2010;285(1):339-348.

20. Shaw BF, et al. Detergent-insoluble aggregates associated with amyotrophic lateral sclerosis in transgenic mice contain primarily full-length, unmodified superoxide dismutase-1. J Biol Chem. 2008;283(13):8340-8350.

21. Kayed R, et al. Common structure of soluble amyloid oligomers implies common mechanism of pathogenesis. Science. 2003;300(5618):486-489.

22. Barlow AD, Nicholson ML, Herbert TP. Evidence for rapamycin toxicity in pancreatic $\beta$-cells and a 
review of the underlying molecular mechanisms. Diabetes. 2013;62(8):2674-2682.

23. McGowan EB, Becker E, Detwiler TC. Inhibition of calpain in intact platelets by the thiol protease inhibitor E-64d. Biochem Biophys Res Commun. 1989;158(2):432-435.

24. Umezawa H, Aoyagi T, Morishima H, Matsuzaki M, Hamada M. Pepstatin, a new pepsin inhibitor produced by actinomycetes. J Antibiot (Tokyo). 1970;23(5):259-262.

25. Klionsky DJ, et al. Guidelines for the use and interpretation of assays for monitoring autophagy. Autophagy. 2012;8(4):445-544.

26. Waguri S, Komatsu M. Biochemical and morphological detection of inclusion bodies in autophagy-deficient mice. Methods Enzymol. 2009;453:181-196.

27. Couce $\mathrm{M}$, et al. Treatment with growth hormone and dexamethasone in mice transgenic for human islet amyloid polypeptide causes islet amyloidosis and $\beta$-cell dysfunction. Diabetes. 1996;45(8):1094-1101.

28. Wu JJ, et al. Mitochondrial dysfunction and oxidative stress mediate the physiological impairment induced by the disruption of autophagy. Aging (Albany NY). 2009;1(4):425-437.

29. Robertson RP. Chronic oxidative stress as a central mechanism for glucose toxicity in pancreatic islet $\beta$ cells in diabetes. J Biol Chem. 2004;279(41):42351-42354.

30. Szabo C, Ischiropoulos H, Radi R. Peroxynitrite: biochemistry, pathophysiology and development of therapeutics. Nat Rev Drug Discov. 2007;6(8):662-680.

31. Komatsu M, et al. The selective autophagy substrate $\mathrm{p} 62$ activates the stress responsive transcription factor Nrf2 through inactivation of Keap1. Nat Cell Biol. 2010;12(3):213-223.

32. Komatsu M, et al. Homeostatic levels of p62 control cytoplasmic inclusion body formation in autophagy-deficient mice. Cell. 2007;131(6):1149-1163.
33. Lau A, et al. A noncanonical mechanism of Nrf2 activation by autophagy deficiency: direct interaction between Keap1 and p62. Mol Cell Biol. 2010;30(13):3275-3285.

34. Baird L, Dinkova-Kostova AT. The cytoprotective role of the Keap1-Nrf2 pathway. Arch Toxicol. 2011;85(4):241-272.

35. Chen XL, et al. Activation of Nrf2/ARE pathway protects endothelial cells from oxidant injury and inhibits inflammatory gene expression. Am J Physiol Heart Circ Physiol. 2006;290(5):H1862-H1870.

36. Park EY, Rho HM. The transcriptional activation of the human copper/zinc superoxide dismutase gene by 2,3,7,8-tetrachlorodibenzo-p-dioxin through two different regulator sites, the antioxidant responsive element and xenobiotic responsive element. Mol Cell Biochem. 2002;240(1-2):47-55.

37. Qiang W, et al. Activation of transcription factor Nrf-2 and its downstream targets in response to moloney murine leukemia virus ts1-induced thiol depletion and oxidative stress in astrocytes. J Virol. 2004;78(21):11926-11938.

38. Abe $\mathrm{H}$, et al. Exendin- 4 improves $\beta$-cell function in autophagy-deficient $\beta$-cells. Endocrinology. 2013;154(12):4512-4524.

39. Masini M, et al. Autophagy in human type 2 diabetes pancreatic $\beta$ cells. Diabetologia. 2009;52(6):1083-1086.

40. Knaevelsrud H, Simonsen A. Fighting disease by selective autophagy of aggregate-prone proteins. FEBS Lett. 2010;584(12):2635-2645.

41. Johansen T, Lamark T. Selective autophagy mediated by autophagic adapter proteins. Autophagy. 2011;7(3):279-296.

42. O'Brien TD, Butler AE, Roche PC, Johnson KH, Butler PC. Islet amyloid polypeptide in human insulinomas. Evidence for intracellular amyloidogenesis. Diabetes. 1994;43(2):329-336.

43. Bjorkoy G, et al. p62/SQSTM1 forms protein aggregates degraded by autophagy and has a pro- tective effect on huntingtin-induced cell death. J Cell Biol. 2005;171(4):603-614.

44. Watanabe Y, et al. p62/SQSTM1-dependent autophagy of Lewy body-like alpha-synuclein inclusions. PLoS One. 2012;7(12):e52868.

45. Welton JL, et al. Proteomics analysis of bladder cancer exosomes. Mol Cell Proteomics. 2010;9(6):1324-1338.

46. Danzer KM, et al. Exosomal cell-to-cell transmission of alpha synuclein oligomers. Mol Neurodegener. 2012;7:42.

47. Lee S, Hur EG, Ryoo IG, Jung KA, Kwak J, Kwak MK. Involvement of the Nrf2-proteasome pathway in the endoplasmic reticulum stress response in pancreatic $\beta$-cells. Toxicol Appl Pharmacol. 2012;264(3):431-438.

48. Uruno A, et al. The Keap1-Nrf2 system prevents onset of diabetes mellitus. Mol Cell Biol. 2013;33(15):2996-3010.

49. Yagishita Y, et al. Nrf2 protects pancreatic $\beta$-cells from oxidative and nitrosative stress in diabetic model mice. Diabetes. 2014;63(2):605-618.

50. Novak I. Mitophagy: a complex mechanism of mitochondrial removal. Antioxid Redox Signal. 2012;17(5):794-802.

51. Komatsu M, et al. Impairment of starvationinduced and constitutive autophagy in Atg7-deficient mice. JCell Biol. 2005;169(3):425-434.

52. Herrera PL. Adult insulin- and glucagon-producing cells differentiate from two independent cell lineages. Development. 2000;127(11):2317-2322.

53. Okada K, et al. The alpha-glucosidase inhibitor acarbose prevents obesity and simple steatosis in sequestosome 1/A170/p62 deficient mice. Hepatol Res. 2009;39(5):490-500.

54. Hohmeier HE, Mulder H, Chen GX, HenkelRieger R, Prentki M, Newgard CB. Isolation of INS-1-derived cell lines with robust ATP-sensitive $\mathrm{K}^{+}$channel-dependent and -independent glucose-stimulated insulin secretion. Diabetes. 2000;49(3):424-430. 